\title{
A HISTÓRIA DE VIDA COMO ALICERCE DA IDENTIDADE DOCENTE: TRAJETÓRIA PESSOAL E PROFISSIONAL DE UMA PROFESSORA
}

\author{
Vanessa Helena Seribelli ${ }^{1}$, Aline de Souza ${ }^{2}$, Cinthia Magda Fernandes Ariosi ${ }^{3}$, Ariadne de Sousa Evangelista ${ }^{4}$ \\ 1Mestra em Educação pelo Programa de Pós-Graduação de Educação da Universidade Estadual Paulista - FCT/UNESP, \\ Presidente Prudente, SP. Professora da Secretaria Municipal de Educação de Campo Grande, MS. E-mail: \\ vanessa_seribelli@hotmail.com \\ ${ }^{2}$ Mestra em Educação pelo Programa de Pós-Graduação de Educação da Universidade Estadual Paulista - FCT/UNESP, \\ Presidente Prudente, SP . Professora da Prefeitura Municipal de Pirapozinho, SP. \\ ${ }^{3}$ Doutora em Educação pelo Programa de Pós-Graduação em Educação da Universidade Estadual Paulista - \\ FFC/UNESP, Marília, SP. Atualmente é docente do Departamento de Educação e do Programa de Pós-Graduação em \\ Educação da Universidade Estadual Paulista - FCT/UNESP, Presidente Prudente, SP. \\ ${ }^{4}$ Doutoranda em Educação pelo Programa de Pós-Graduação em Educação da Universidade Estadual Paulista - \\ FCT/UNESP, Presidente Prudente, SP. Tutora do Curso Semipresencial de Pedagogia da Universidade Anhanguera, \\ Polo de PresidentePrudente, SP.
}

\section{RESUMO}

Este trabalho versa sobre a formação de professores, um campo de investigação bastante explorado nos dias atuais mas com posicionamentos por vezes contraditórios. $O$ sujeito da pesquisa é uma professora que atua na educação básica com mais de dez anos de carreira. A metodologia empregada foi um estudo de caso, na abordagem qualitativa. Como procedimento de coleta de dados foi utilizado a entrevista narrativa. A pesquisa, que teve como objetivo compreender a trajetória de formação e trabalho de uma professora e como esse processo influenciou na sua identidade docente, apontou nos resultados que questões financeiras interferem na escolha e na permanência da carreira e que acúmulo de funções atribuídas ao professor é uma das causas do desânimo em relação a profissão.

Palavras-chave: Formação de professores. História de vida. Identidade docente. Carreira docente.

\section{THE HISTORY OF LIFE AS ALICERCE OF THE TEACHING IDENTITY: PERSONAL AND PROFESSIONAL TRAJECTORY OF A TEACHER}

\begin{abstract}
This work deals with teacher training, a field of research that is explored in the present day but with contradictory positions. The subject of the research is a teacher who works in basic education with more than ten years of career. The methodology used was a case study, in the qualitative approach. As a data collection procedure, the narrative interview was used. The research, which aimed to understand the trajectory of training and work of a teacher and how this process influenced their teacher identity, pointed out in the results that financial issues interfere in the choice and permanence of the career and that the accumulation of functions attributed to the teacher is one of the causes of discouragement in relation to the profession.
\end{abstract}

Keywords: Teacher training. Life's history. Teachingidentity. Teachingcareer.

\section{LA HISTORIA DE VIDA COMO BASE DE LA IDENTIDAD DOCENTE: TRAYECTORIA PERSONAL Y PROFESIONAL DE UNA PROFESORA}

\section{RESUMEN}

Este trabajo versa sobre la formación de profesores, un campo de investigación bastante explorado en los días actuales, pero con posicionamientos a veces contradictorios. El sujeto de la investigación es una profesora que actúa en la educación básica con más de diez años de carrera. La metodología empleada fue un estudio de caso, en el abordaje cualitativo. Como procedimiento de recolección de datos se utilizó la 
entrevista narrativa. La investigación, que tuvo como objetivo comprender la trayectoria de formación y trabajo de una profesora y cómo ese proceso influenció en su identidad docente, apuntó en los resultados que las cuestiones financieras interfieren en la elección y en la permanencia de la carrera y que la acumulación de funciones atribuidas al profesor es una de las causas del desánimo en relación a la profesión.

Palabras clave: Formación de profesores. Historia de vida. Identidad docente. Carrera docente.

\section{CONTEXTUALIZANDO A PESQUISA}

A formação de professores é um campo de pesquisa amplo e carece de aprofundamento em alguns aspectos, desta forma nasceu o interesse em desenvolver uma investigação mais minuciosa sobrea temática. Motivadas por uma disciplina do Programa de Pós-Graduação em Educação da Faculdade de Ciências e Tecnologia da Universidade Estadual Paulista "Júlio de Mesquita Filho" foi proposto essa investigação com base nos seguintes questionamentos: Como a trajetória de vida, saberes e experiências contribuíram para a formação docente? De que maneira a formação do professor, inicial e continuada, interfere na sua prática pedagógica? Quais os principais motivadores e desmotivadores da carreira?

Para responder esses questionamentos, buscou-se compreender os conceitos de profissionalização e profissionalidade docente; a dimensão técnica, estética e política da função do professor; o grau de autonomia e especificidades da prática do ensino e da formação do professor na sociedade do conhecimento, o mal-estar e bem-estar docente, a necessidade da formação continuada e o campo de pesquisa formação de professores no Brasil.

Na busca de compreender tais conceitos, embasamos nossa fundamentação téorica nos seguintes autores: André (2010), Contreras (2012), Cortesão (2002), Diniz (2013), Ferreira (2003), Gatti, Barreto e André (2011), Hargreaves (2004), Jesus (2002), Lopes (2001), Rios (2001), Schon (1997), Zainco (2003), entre outros.

Neste sentido, o objetivo geral desse estudo foi compreender a trajetória de formação e trabalho de uma professora. Para alcançá-lo, utilizamos como abordagem metodológica a pesquisa qualitativa.Para Chizzotti (2003),

O termo qualitativo implica uma partilha densa com pessoas, fatos e locais que constituem objetos de pesquisa, para extrair desse convívio os significados visíveis e latentes que somente são perceptíveis a uma atenção sensível e, após este tirocínio, o autor interpreta e traduz em um texto, zelosamente escrito, com perspicácia e competência cientificas, os significados patentes ou ocultos do seu objeto de pesquisa (CHIZZOTTI, 2003, p.221).

Conforme André (2008, p.29), se o pesquisador "[...] quiser entender um caso particular levando em conta seu contexto e complexidade, então o estudo de caso se faz ideal". A autora afirma que na abordagem qualitativa, a unidade escolhida para ser estudada pode ser representativa de outros casos ou completamente distinta, o importante é que a escolha seja bem delimitada, justificada e descrita.

Como instrumento de coleta de dados utilizamos a entrevista narrativa. Conforme propõe Gil (2008), Clandinin e Connelly (2011), Momberger (2006), esse procedimento é viável a quem deseja estudar um tema profundamente e consente maior liberdade ao entrevistado e ao entrevistador permite que mantenha o foco.

Segundo Sousa (2014) é preciso garantir que os direitos do entrevistado sejam respeitados e que haja ética na pesquisa, com esse intuito coletamos a assinatura da entrevistada no Termo de Consentimento Livre Esclarecido (TCLE), que permite comprovar a disposição em participar da pesquisa e a consciência do que esse ato implica.

A entrevista com a professora se realizou com base em um roteiro composto por vinte questões, organizadas em três subtemas que serão apresentados posteriormente. Essas questões serviram para nortear o trabalho sem perder o foco,porémnão se tratou de questões fechadas e pontuais que limitassem a resposta da entrevistada. 
Na segunda seção desse texto discutiu-se a fundamentação teórica, os conceitos e autores que pautaram as análises. Os professores têm sido alvo, principalmente da mídia na culpabilização das falhas da qualidade da educação brasileira. Responsabilizar o professor e sua formação não auxilia na solução dos problemas. É preciso compreender o contexto em que essa situação se insere e em que condição histórica e social a educação brasileira se encontra, para a busca da melhoria.

$\mathrm{Na}$ terceira seção, aponta-se o caminho percorrido da pesquisa, a metodologia. Evidenciase quais os critérios para a escolha do sujeito, os recursos e procedimentos utilizados para a coleta de dados e o percurso para a concretização desta.

$\begin{array}{crr}\mathrm{Na} & \text { quarta seção, apresenta-se e } \\ \text { analisam-se } & \text { os } & \text { dados coletados, }\end{array}$ contextualizandoa trajetória de vida, formação inicial e continuada, trabalho docente e desafios profissionais de uma professora em exercício no ensino fundamental público de Presidente Prudente - SP. Problematizaram-se esses fatores à luz da teoria estudada.

Por fim, concluiu-se as análises, fazendo apontamentos para aqueles que pretendem colaborar com o campo de formação de professores, numa perspectiva crítica e contextualizada.

\section{A CONSTRUÇÃO DA IDENTIDADE DOCENTE: PRESSUPOSTOS TEÓRICOS}

Ao estudar sobre a profissão do professor articulando com o desempenho do papel social e político na trajetória de formação, contextualizou-se os aspectos que envolvem as características do ofício docente e a constituição dessa profissão enquanto campo de pesquisa. Inicialmente a profissão do professor foi marcada por peculiaridades que traziam ao serviço um ganho de autonomia, categorizando-os como profissionais específicos de uma área de conhecimento. No entanto, essa autonomia se caracterizou como ilusória, visto que:

[...] a consideração de
que os docentes,
enquanto categoria,
sofreram ou estão
sofrendo uma
transformação, tanto
nas características de
suas condições de
trabalho como tarefas

que realizam que os aproxima cada vez mais das condições e interesses da classe operária [...] (CONTRERAS, 2012, p. 38).

Esta situação deriva das pressões que são introduzidas na prática do professor, ocasionadas pelo cumprimento excessivo de tarefas sem permitir a reflexão sobre o que está sendo realizado. Deste modo, Torres (1991, p.199 apud CONTRERAS, 2012, p.42), apresenta duas percepções sobre os efeitos dessa falta de autonomia dos professores:

[...] De um lado, favorece a rotinização do trabalho, já que impede o exercício reflexivo, empurrado pela pressão do tempo. De outro, facilita o isolamento dos colegas, privados de tempo para encontros que se discutem e se trocam experiências profissionais, fomentando-se dessa forma o individualismo [...].

Neste sentido, o autor ainda salienta que o professor "[...] ao renunciar à sua autonomia como docente, aceita a perda do controle sobre seu trabalho e a supervisão externa do mesmo". (CONTRERAS, 2012, p.43). Com isso, esse profissional transfere o controle de suas ações para o estado que padroniza o ensino e as práticas pedagógicas marcadas pelas características da "proletarização docente". Porém, cabe ao professor compreender essas situações que envolvem suas tarefas, e refletir sobre elas criando estratégias para o sucesso de suas propostas. Fazendo essa articulação, esses profissionais trarão qualidade para o seu trabalho e poderão usufruir da autonomia tecida por eles.

Diante disso, observa-se o quanto "[...] a profissionalização pode encerrar um argumento corporativista, que identifica a autonomia com o isolamento e a não intromissão [...]". (CONTRERAS, 2012, p.80). Por isso, ao se formar professor, é preciso ter clarezaque no embate com a profissionalização, está a profissionalidade defendida pelo autor e refere-se às qualidades e 
às funções peculiares do trabalho docente, que "não é só descrever o desempenho do trabalho de ensinar, mas também expressar valores e pretensões que se deseja alcançar e desenvolver nesta profissão." (CONTRERAS, 2012, p.82).

Nesta perspectiva, Rios (2001) alerta para a compreensão da identidade profissional do professor através das dimensões que estão interligadas em sua prática pedagógica. Mesmo tratando de forma conceitual, essas dimensões ganham sentido quando são descobertas e incorporadas na vivência do professor.

A dimensão técnica "[...] reporta, assim, à realização de uma ação, a uma certa forma de fazer algo, a um ofício. No seu ofício, alguém faz alguma coisa - aí se requer ou se demonstra alguma habilidade" (RIOS, 2001, p. 94). A dimensão estética define que "[...] a sensibilidade e a criatividade não se restringem ao espaço da arte. Criar é algo interligado a viver, no mundo humano. A estética é, na verdade, uma dimensão da existência, do agir humano" (RIOS, 2001, p. 97).

A dimensão política está configurada na polis onde se fundamenta as relações humanas, e ligadas a elas a dimensão ética que possui caráter reflexivo e não normativo. "[...] É no espaço político que transita o poder, que se configuram acordos, que se estabelecem hierarquias, que se assumem compromissos. Daí sua articulação com a moral - e a necessidade de sua articulação com a ética" (RIOS, 2001, p. 104).

Mesmo abrangendo essas dimensões na prática pedagógica do professor, ainda é reconhecível que esta categoria sofra com algumas indagações e preocupações que orientam a construção de sua autonomia e identidade. Isto é reflexo de um sistema educacional cada vez mais universal, com modelos pedagógicos padronizados, fazendo com que o o processo de conhecimento aconteça cada vez mais de forma acelerada. Nesta visão, Hargreaves (2004) define a sociedade do conhecimento como uma sociedade de aprendizagem. $\mathrm{O}$ autor ainda argumenta que "[...] as nossas escolas devem, portanto, estimular também a solidariedade, a identidade comunitária e cosmopolita que irão contrabalançar os efeitos destruidores da economia do conhecimento" (HARGREAVES, 2004,p.13).

Com o objetivo de lidar com essas novas relações, é necessário que haja preparação das escolas e a formação dos profissionais que nelas atuam. Mas, na maioria das vezes:

[...] as nossas escolas não
estão a preparar os jovens
nem para funcionarem
bem na economia de
conhecimento, nem para
viverem bem numa
sociedade civil forte. Em
vez de promoverem a
invenção econômica e a
integração social,
demasiadas escolas têm
vindo a enredar-se em
regulamentos e rotinas de
estandardização sem
chama (HARGREAVES,
2004, p.14).

Contextualizando a função da escola no alcance do interesse e efetivação do ensino pelo alunado, dentro desta perspectiva de mudança, Cortesão $(2002$, p. 28$)$ argumenta que:

[...] muitos destes alunos
foram socializados noutros
valores, de acordo com
outras regras, tiveram
outro tipo de vivências,
têm outros
conhecimentos, possuem
outros interesses, outras
inquietações, outras
formas de estar na vida.
Obrigados a ir a uma
escola que não se obriga a
ela própria a mudar para
ser capaz de os atrair e de
lhes ser útil [...]

Talvez isso deva ao despreparo da escola e insatisfação do professor em relação ao ensino, pois os alunos acessam fora da escola outras estratégias de "[...] divertimentos e mesmo fontes de informação muito mais aliciantes do que podem ser oferecidas pelos professores" (CORTESÃO, 2002, p.29).

Deste modo, percebe-se que essas situações provocam no professor um sentimento de mal-estar, ocasionado pelas condições de trabalho, como também, pela falta de autonomia em se desvencilhar de certos modos que atrapalham o seu desenvolvimento. Assim, Lopes (2001, p. 7) conceitua o mal-estar como "[...] a existência de uma crise na docência, com origem em mudanças nos parâmetros do exercício profissional e com impacto nefasto no equilíbrio 
pessoal dos professores e na qualidade da educação".

É inevitável que nas relações humanas os indivíduos não sejam provocados ao stress, visto que as condições são variáveis: as opiniões são divergentes, as condições de trabalho nem sempre são favoráveis, o planejamento precisa ser flexível, exigindo do professor um manejo espontâneo etc. Mas o que precisa levar em consideração é a maneira como o sujeito lida com esse sentimento, isso "[...] significa ser capaz de transformar uma situação stressante numa outra não stressante, mudando a situação ou as percepções que a pessoa tem da situação ou, ainda, treinando as competências necessárias" (LOPES, 2001, p. 18).

Quando o professor compreende as estratégias de superação do stress, buscando soluções individuais e coletivas para a prevenção do mal-estar, o mesmo consegue passar pelas dificuldades gerando sucesso em sua carreira profissional. Essa característica é marcada pelo bem-estar docente, que segundo Jesus (2002, p. 47) é resultado de um trabalho coletivo, onde os professores:

[...] aprendem muito com a experiência pessoal, mas também podem aprender com o conhecimento da experiência de colegas de trabalho. No entanto, para que o trabalho em equipe resulte, é necessário que os professores apresentem uma atitude de autenticidade, empatia, cooperação e valorização das experiências e sugestões apresentadas pelos colegas.

Ou seja, o professor não é um ser isolado, para além da socialização que estabelece com a comunidade, escola e demais colegiados, proporcionando a sua formação pessoal dotada de saberes específicos, o mesmo precisa estar em contínuo desenvolvimento profissional.

Contrapondo as terminologias reciclagem, treinamento, aperfeiçoamento e capacitaçãoexplicadas por Marin (1995) onde os seus sentidos muitas vezes parecem ocultos nos cursos de formação de professores, a autora corrobora a importância de refletirmos sobre os objetivos que estes cursos propõe. No sentido de promover $o$ desenvolvimento profissional, Marin (1995) apresenta três conjuntos de termos que podem colaborar para a valorização dos professores e a superação das dificuldades, são eles: educação permanente, formação continuada e educação continuada.

A formação continuada pode ser objetivada por interesses particulares ou de um determinado grupo, mas é imprescindível que os profissionais envolvidos tenham clareza do seu papel social e político na formação dos alunos para a promoção da educação pública de qualidade.Fazendo articulações com os saberes dos professores e a importância da formação inicial e continuada na sociedade atual, buscou-se compreender em Hargreaves (2004, p.22) a explanação de que:

Ensinar na sociedade de
conhecimento requer
níveis de competências e
de reflexão, muito para
além dos utilizados para
meramente debitar o
currículo prescrito por
outros e os resultados dos
testes estandardizados.
Requer maturidade
pessoal e intelectual que
levam anos a desenvolver-
se [...] ensinar na
sociedade de
conhecimento deve ser
uma carreira de primeira
escolha, um trabalho para
intelectuais adultos, um
compromisso a longo
prazo, uma missão social,
o emprego de uma vida.
Tudo o que for menos do
que isto deixa a nossa
visão abaixo da sociedade
de conhecimento e no
ensino nunca devemos
contentar-nos com menos.

Estar em constante formação, é ter a certeza que somos sujeitos inacabados e transformados pelas experiências adquiridas no decorrer da vida. Desta forma, Heidegger (1987, p. 143 apud LARROSA BONDIA, 2002, p. 25) ressalta que "[...] fazer uma experiência com algo significa que algo nos acontece, nos alcança; que se apodera de nós, que nos tomba e nos transforma". Ainda segundo o autor, a experiência é algo que nos modifica, e não provoca o acomodamento, pois as nossas estruturas não serão mais as mesmas quando 
estão em contato com novos conhecimentos. Assim sendo, destaca-se a importância da formação continuada que permite a reflexão de nossas ações no sentido da práxis, como também da socialização de conhecimento entre os pares no espaço escolar.

Compreendendo a formação de professores como um campo de estudo, André (2010, p.174) enfatiza que "[...] pela falta de espaço específico, a produção científica sobre a formação docente ficou aninhada, por um certo período de tempo, no campo da didática. Pouco a pouco, porém, essa produção foi crescendo e tomando vida própria". E apoiado em García (1999), André (2010) apresenta cinco critérios do processo de constituição do campo de formação de professores - a existência de objeto próprio, metodologia dos estudos, criação de um grupo de cientistas com códigos e interesses comuns, incorporação ativa dos participantes na pesquisa e reconhecimento do papel fundamental na formação docente. Portanto ao concluir a análise desse processo, André (2010) apresenta alguns pontos que faltam para avançar nesse campo, deste modo, o autor destaca que ainda

[...] há muito que
aperfeiçoar na pesquisa
para que haja uma
contribuição efetiva na
configuração do campo
[...] torna-se necessário
dar um passo além,
aprofundar as análises e
interpretações, de modo
que se possa gerar um
conhecimento mais
abrangente e consistente.
(ANDRÉ, 2010, p. 180)

E quanto aos resultados das pesquisas "[...] há muito que melhorar, tanto na forma de apresentação quanto na precisão [...]" (ANDRÉ, 2010 , p. 180). Contudo, é perceptível reconhecer que o campo de formação de professores é recente, e por isso recebe algumas críticas quanto ao foco das investigações. Sobre esses julgamentos, DinizPereira (2013, p. 149) constata que:

[...] entre as pesquisas
sobre formação de
professores no país, a
parcela que se dedica à
questão da identidade
docente é ainda muito
pequena. É importante

ressaltar que a diversidade de perspectivas teóricas sob as quais essa questão é abordada sugere uma tímida articulação entre os pesquisadores e certa fluidez no campo.

Conceituando a formação de professores na visão de García (1999, p. 19) que configura "[...] tal como muitos outros, na nossa área de conhecimento, é susceptível de múltiplas perspectivas." É indispensável afirmar que para a efetivação dessa formação "[...] é preciso que se produzam mudanças através de uma intervenção na qual há participação consciente do formando e uma vontade clara do formando e do formador de atingir os objetivos explícitos" (GARCÍA, 1999, p. 21). Deste modo, incluímos a necessidade de formação de professores reflexivos, no sentido da práxis, onde o formador e o receptor dessa formação devem estar imbuídos em um mesmo objetivo, visando a garantia da educação pública de qualidade e a formação integral de sujeitos críticos.

Fundamentado nos conceitos de Schön (1997) que articula a prática pedagógica do professor através do conhecimento na ação, reflexão na ação e reflexão na ação e sobre a ação, princípios estes que contrapõem a ideia da racionalidade técnica (baseada na reprodução de modelos prontos sem o exercício da reflexão). Quando os professores "[...] tentam criar condições para uma prática reflexiva, é muito possível que se venham a confrontar com a burocracia escolar [...]. O sistema burocrático e regulador da escola é construído em torno do saber" (SCHÖN, 1997, p. 87). É no desenvolvimento de uma prática reflexiva, que o professor oportuniza sua autonomia e constitui a sua identidade docente, estimulado por sua criatividade no caminho da formação continuada.

Ainda é importante ressaltar que o contexto de universalização no qual estamos inseridos, provoca na formação continuada um desafio ligado aos modos econômicos, sociais, políticos e culturais da população. Sobre isso, Ferreira $(2003$, p. 26) destaca que "[...] cada vez mais faz-se necessário uma formação continuada e de qualidade para um novo "cidadão do mundo" [...]". Diante de uma sociedade globalizada, notamos a função da universidade enquanto local de formação inicial 
e continuada de professores no desenvolvimento da capacidade de pensamento crítico destes profissionais. Ao promover a reflexão da prática docente no decorrer de sua formação contínua e permanente, Zainco (2003, p. 194) diz que o professor:

[...] estará em condições de pensar em novas formas de organização curricular, que superem a fragmentação hoje existente, bem como em novas metodologias de ensino, de avaliação da aprendizagem, de utilização dos modernos recursos da tecnologia da informação e da comunicação sem com isso estar apenas desenvolvendo um novo fazer instrumental.

Constituindo o gerenciamento de formação contínua, o professor poderá se aperfeiçoar permanentemente em busca de novos conhecimentos que supram as necessidades de compreensão da realidade proposta, assumindo assim, o papel de sujeito reflexivo e crítico de suas ações, promovendo a transformação de sua prática no intuito de contribuir com a construção humana do mundo.

Aprofundando os conhecimentos sobre a formação de professores, Gatti, Barreto e André (2011) apresentam um mapeamento das produções acadêmicas realizado por André (2010) que indica o aumento de estudos sobre o campo partir do ano 2000, com foco no professor, seus saberes, práticas e opiniões. As autoras ainda argumentam que ouvir os professores parece ser positivo, se o que pretende descobrir com eles está articulado com o alcance da aprendizagem significativa do aluno. Deste modo, ainda seguindo as percepções de Gatti, Barreto e André (2011), que apontam dois tipos de preocupações sobre essa mudança de foco no campo da formação de professores, apresentando que, devem ter investigações também na formação inicial de professores, afim de formar profissionais competentes para trabalhar na sociedade atual. Por outra parte, as pesquisas não podem demonstrar somente as ideias dos professores como se fossem os únicos responsáveis pela melhoria da qualidade da educação. Portanto Gatti, Barreto e André (2011, p. 15) concluem que:

[...] há outros elementos igualmente importantes como a valorização social da profissão, os salários, as condições de trabalho, a infraestrutura das escolas, as formas de organização do trabalho escolar, a carreira - que devem fazer parte de uma política geral de apoio aos docentes. São muitos fatores que podem ser esquecidos, nem desconsiderados no delineamento de políticas para os professores.

Contudo, assinala-se que estes elementos interligados devem ser considerados nas pesquisas desenvolvidas no campo de formação de professores, pois são fatores que refletem na prática docente e constitui em desafios enfrentados por eles, fundamentando a construção de sua autonomia e identidade profissional.

\section{CAMINHOS PERCORRIDOS}

A partir das interlocuções teóricas apresentadas anteriormente, que elencaram os fatores interligados a construção da autonomia e identidade do professor, apresenta-se aqui o caminho desenvolvido para a realização deste estudo, com o intuito de compreender a trajetória de formação e trabalho de uma professora.

Nesta investigação, foramestabelecidos alguns critérios na escolha do professor participante, como:

- Atuar ou ter atuado na educação básica (educação infantil, ensino fundamental e médio);

- Ter experiência profissional no magistério, de no mínimo dez anos;

- Ser um profissional de boa reputação entre seus pares, comunidade e alunos, ou seja, com experiências e contribuições significativas na sua trajetória. 
A professora foi escolhida por atender todos os critérios propostos, é atuante na primeira etapa do ensino fundamental, tem mais de dez anos de experiência nesse nível de ensino e é considerada entre os pares, pela gestão escolar e pela comunidade local uma professora "exemplo". Também foi selecionada por conveniência, haja vista que, na época da entrevista, trabalhava na mesma escola de uma das pesquisadoras, sendo assim, os critérios mais fáceis de serem observados e atendidos.

A professora foi contatada por telefone, por ser período de recesso escolar. Ela aceitou participar da entrevista e preferiu que o contato fosse via e-mail, devido ao fator tempo e em função de seus compromissos pessoais e profissionais. Neste mesmo momento, explicitou-se os objetivos, a metodologia e os procedimentos do trabalho.

Para a coleta de dados, foi elaborado um $\mathrm{TCLE}^{1}$, respeitando os direitos éticos da professora, e após esta introdução, construiuse um roteiro de entrevista dividido em três aspectos: identificação do sujeito, formação e exercício da docência.

Inicialmente, pretendia-se realizar a entrevista utilizando os recursos audiovisuais, porém, não foi possível, visto que o sujeito da pesquisa tem jornada dupla de trabalho, impossibilitando um agendamento sem interrupções.

Dessa maneira, o roteiro de entrevista foi enviado por e-mail e quando respondido, houve a oportunidade de retomar com a professora questões referentes às dúvidas que surgiram no decorrer da análise. Esse processo de respostas e retomadas durou, aproximadamente, três meses. As trocas se materializaram através de doze e-mails entre as pesquisadoras e a professora entrevistada. Em média, foram enviados e respondidos dois emails por semana. Mesmo não sendo possível utilizar os recursos audiovisuais no desenvolvimento da entrevista, eles são um excelente caminho para a compreensão de um diálogo mais significativo.

Momberger (2006, p. 363) compreende a narrativa não somente como o "[...] sistema simbólico no qual o pôr em forma da existência encontraria uma expressão: a narrativa é o lugar onde o indivíduo humano toma forma,

\footnotetext{
${ }^{1}$ Termo de Consentimento Livre e Esclarecido
}

onde ele elabora e experimenta a história de sua vida".

Definindo a formalidade de uma entrevista narrativa, Gil (2008, p.109) argumenta que é "[...] uma forma de interação social. Mais especificamente, é uma forma de diálogo assimétrico, em que uma das partes busca coletar dados e a outra apresenta como fonte de informação". A partir disso, o autor apresenta que as entrevistas podem ser classificadas em categorias: informais, focalizadas, por pauta e formalizadas. Portanto, a modalidade que mais se aproxima da entrevista narrativa é a entrevista focalizada, que conforme Gil (2008, p.12):

[...] enfoca um tema bem especifico. $O$ entrevistador permite ao entrevistado falar livremente sobre 0 assunto, mas, quando se desvia do tema original, esforça para sua retomada [...] é bastante empregado em situações experimentais, com objetivo de explorar a fundo alguma experiência vivida em condições especiais [...].

Como possibilidade de uma pesquisa epistemológica, o trabalho com narrativas de professores proporciona entender o mundo a partir de uma perspectiva histórica e narrada por um sujeito que possui características subjetivas. Deste modo, Clandinin e Connelly (2011, p. 48) enfatizam que a vida “[...] é preenchida de fragmentos narrativos, decretados em momentos históricos de tempo e espaço, e refletidos e entendidos em termos de unidades narrativas e descontinuidades". Ao escrever sobre a sua trajetória o individuo pode representar e entender a sua vida a partir da experiência. A "[...] experiência é o que estudamos, e estudamos a experiência de forma narrativa porque $o$ pensamento narrativo é uma forma-chave de experiência e um modo-chave de escrever sobre ela". (CLANDININ; CONNELLY, 2011, p. 48).

Um aspecto fundamental do trabalho com narrativas na visão de Queiroz $(1988$, p.20) configura em uma "técnica cuja aplicação demanda longo tempo [...]". Esta organização possibilita um contato contínuo entre o pesquisador e participante, por isso a 
investigação não se encerra quando o investigador possuir a resposta desejada. Esse processo exige respeito quanto à reflexão de ambos na produção do conhecimento articulado com o sucesso da prática.

De outro modo, o tempo diz respeito à representação do sujeito em um determinado lugar, caracterizado por um conjunto de situações inseridas no decorrer de sua vida. Nessa perspectiva Clandinin e Connelly (2011) apontam os aspectos da tridimensionalidade na pesquisa narrativa, considerando o lugar, o espaço e o tempo onde o indivíduo atua. Ainda os autores abordam a responsabilidade dos pesquisadores em respeitar estes aspectos no trabalho com os sujeitos pesquisados, onde "[...] seguindo a noção de espaço tridimensional da pesquisa narrativa, o escritor tenta compor um texto olhando retrospectiva e prospectivamente, introspectiva e extropectivamente, situando a experiência dentro de um lugar" (CLANDININ; CONNELLY, 2011, p. 187).

Diante disso, Sousa (2014) ressalta que o trabalho com narrativas solicita alguns cuidados, tanto por parte dos pesquisadores, como também dos colaboradores. Ainda usando a ideia do autor, que consolida a utilização de termo ou carta de cessão de direitos ao realizar os diálogos com os sujeitos pesquisados, apresentando também outra opção "[...] em função da impossibilidade de utilização do nome do/da colaborador/a no relatório de pesquisa ou para efeitos de publicação, discutir com o/a mesmo/a possibilidade de identificação na pesquisa, a fim de preservar sua identidade" (SOUSA, 2014, p.43).

Portanto, ao trabalhar com os dados da entrevista realizada, foi necessário tomar estes cuidados apontados pelos autores acima mencionados, por isso, utilizou-se o nome fictício Joana. As análises foram realizadas respeitando a subjetividade da professora fazendo conexões com autores que contribuem para a reflexão sobre as questões que permeiam os acontecimentos históricos e sociais na formação e trabalho de Joana.

Contudo, foi analisadoo modo como foi desenvolvida a entrevista, e constatou-se quea utilização de recursos audiovisuais nas pesquisas com narrativas, é mais proveitoso, pois estes permitem maior compreensão dos aspectos que envolvem os sentimentos dos sujeitos pesquisados.A respeito disso, Clandinin e Connelly (2011) argumentam sobre a multiplicidade de vozes presente no desenvolvimento com pesquisas narrativas, no sentido de que:

[...] nós, e nossos
participantes, vivemos e
contamos muitas histórias.
Nós todos somos
personagens com
múltiplos papéis que
falamos de dentro de
múltiplos enredos. Como
tentamos capturar esta
multiplicidade, precisamos
considerar as vozes
ouvidas e não ouvidas. Ou,
para olhar a voz de outra
forma, podemos incluir a
voz do participante de tal
forma que o contexto do
texto de pesquisa
obscureça ou silencie
importantes partes da voz
do participante [...]
(CLANDININ; CONELLY,
2011, p. 195).

Ao perceber estas situações no percurso da entrevista narrativa, analisou-se com maior vitalidade a importância que o indivíduo estabelece aos acontecimentos por meio de gestos e interrupções da fala, sendo possível mudar o caminho da entrevista (sem perder o foco da pesquisa), possibilitando um diálogo contínuo e significativo.

\section{DESCOBERTAS, ANÁLISES E CONSTATAÇÕES}

A literatura ao trazer trabalhos de autores como Nóvoa (1992), Demartini (1988), Queiroz (1988), Dubar (1997), entre outros, oferece suporte para trabalhar com a metodologia de histórias de vida no campo educacional. Tendo a educação como tema central e apresentando abordagens metodológicas consistentes, os autores supracitados são algumas das referências utilizadas por pesquisadores que pretendem desenvolver trabalhos de alta credibilidade.

Todavia, Queiroz (1988, p. 20) define a história de vida, como:

$\begin{array}{lrr}\text { [...] o relato de um } \\ \text { narrador } & \text { sobre } & \text { sua } \\ \text { existência } & \text { através } & \text { do } \\ \text { tempo, } & \text { tentando } \\ \text { reconstituir } & & \text { os }\end{array}$


acontecimentos que vivenciou e transmitir a experiência que adquiriu. Narrativa linear e individual dos acontecimentos que nele considera significativos, através dela se delineiam as relações com os membros de seu grupo, de sua profissão, de sua camada social, de sua sociedade global, que cabe ao pesquisador desvendar.

Ao analisar algumas pesquisas, foi possível perceber um crescimento de trabalhos concentrados em investigar a vida ou desenvolvimento pessoal dos professores, carreiras e percursos profissionais, profissionalização e identidades docentes, ciclos de vida e experiência docente, memórias, relação entre o universo profissional e outros universos socioculturais (ANDRÉ, 1997).

A entrevista solicitava àJoana, respostas sobre sua trajetória acadêmica, desde o período em que ingressou na escola quando criança, até os dias atuais, incluindo informações como formação inicial e continuada, particularidades que interferiram e/ou interferem em seu desenvolvimento profissional entre outros aspectos.

A professora participante, nasceu em 1970 e hoje, aos 47 anos de idade, atua como professora efetiva no ensino fundamental $\mathrm{I}^{2} \mathrm{em}$ duas escolas públicas do município de Presidente Prudente - SP, sendo uma delas conveniada ao estado de São Paulo.

Quando criança, não teve acesso à educação infantil, já que na sua cidade não existia nenhuma escola com esse segmento de ensino. No entanto, a professora relata que tinha três irmãos mais velhos, que a estimulava a aprender. Quando iniciou os estudos no 1응 ano do ensino fundamental, na época segmentado como $1 \underline{a}$ série, em uma escola pública da cidade de Presidente Bernardes - SP, já sabia escrever seu nome, e tinha noções de números e letras. Nessa escola, Joana estudou até o final do ensino fundamental II.
${ }^{2}$ Segundo a Legislação Brasileira (LEI n. 9394/96) o Ensino Fundamental é composto por dois ciclos, sendo o Ciclo I do primeiro ao quinto ano e o Ciclo II do sexto ao nono ano.
Por ser uma cidade pequena, conhecia muitas crianças da minha idade e maiores. ĺamos à escola, caminhando. Sempre gostei de aprender, ouvir histórias, resolver problemas matemáticos, saber sobre os seres vivos (reprodução desenvolvimento). $\quad A$ escola era um lugar de encontro, aprendizagem, alegria com os amigos.(JOANA, 2017).

A narrativa da professora traz à tona os aspectos sobre a trajetória da educação infantil no Brasil. Nessa época essa etapa de ensino não era considerada como um espaço de direito da criança, apenas como garantia de acesso aos filhos dos trabalhadores. Outro fator está relacionado à feminização do magistério e a falta de qualificação para a função. Atualmente a educação infantil é vista como importante para o desenvolvimento humano e se desperta como essencial em várias regiões brasileiras, mesmo as de difícil acesso, assegurando o direito da criança a se desenvolver integralmente por profissionais com formação específica. Um exemplo que denuncia essa situação, é o citado por Joana, em que seus irmãos à ensinavam em casa. Não era incomum casos como esse acontecerem. A escola de educação infantil era por muitos considerada como uma etapa desnecessária ao desenvolvimento da criança, haja vista que considerado importante era aprender a ler e a escrever e isso só teria início no ensino fundamental I.

Ainda hoje vemos a educação infantil desvalorizada, por inúmeros fatores de ordem social, política, econômica, cultural. No entanto, a Emenda Constitucional no. 59, de 11 de novembro de 2009 estabelece que:

Art. 208. O dever do Estado com a educação será efetivado mediante a garantia de:

I - educação básica obrigatória e gratuita dos 4 (quatro) aos 17 (dezessete) anos de idade, assegurada inclusive sua oferta gratuita para todos os que a ela não tiveram 
acesso na idade própria. (BRASIL, 2009, p.1)

Apesar de parecer caminhar em passos lentos, a emenda representa um avanço significativo na educação, uma vez que serve de respaldo para evitar que etapas sejam rompidas, como no caso de Joana, que não teve acesso a educação infantil.

No ensino médio, Joana relata que continuou a estudar na rede pública de ensino, porém em outra escola. Nesse período de sua vida, a rotina era a seguinte: as aulas do ensino médio ocorriam no período matutino, sendo o 1 은 ano chamado de ensino básico e a partir do 20 ano, os alunos tinham a opção de cursar o magistério paralelamente ao ensino médio. $\mathrm{E}$ assim aconteceu. Joana frequentava as aulas do colegial ${ }^{3}$ durante o dia e o magistério ${ }^{4}$ durante a noite.

Sobre as razões/motivações que fizeram com que Joana optasse pelo magistério, a mesma lembra que desde a infância tinha facilidade para compreender os conteúdos e que gostava de auxiliar os colegas que tinham dificuldades de aprendizagem, além disso, a escolha do curso poderia ser uma maneira de conseguir entrar no mercado de trabalho e custear seus estudos posteriormente, quando viesse a cursar uma faculdade, já que sua família não tinha condições financeiras para ajudá-la.

A admiração por pessoas próximas que atuavam no cenário educacional, também foi um dos motivos que contribuíram para a escolha da profissão.

Tinha conhecidos que
eram professores: Tia,
vizinha, irmã. Eu as
admirava. E como havia
uma incerteza se entraria
de primeira em um curso
superior público, porque
não tinha possibilidades de
pagar, optei por fazer o
magistério, que poderia
ser uma forma de entrar
no mercado de trabalho e,
se necessário, pagar meus
estudos na Universidade.
Minha turma era animada,
por ser noturno, alguns

${ }^{3}$ Expressão utilizada pela entrevistada.

${ }^{4}$ Curso Normal destinado a Formação Inicial de Professores em nível médio. trabalhavam e depois vinham para a escola. Tinham poucos meninos. $A$ maioria se dedicava por aprender e realizar os estágios e trabalhos propostos(JOANA, 2017).

A diminuição da procura, por parte dos jovens, pela profissão de professor, tem se tornado objeto de preocupação nos últimos anos. De acordo com Gatti e Barretto (2009), 39\% dos alunos dos cursos de licenciatura que responderam ao questionário do Exame Nacional de Desempenho de Estudante (ENADE) em 2005 estavam na faixa que compreende até três salários mínimos de renda familiar, ou seja, alunos provenientes de classes menos favorecidas, fator que contribui para a escolha da docência, uma vez que os cursos de licenciaturas são mais acessíveis financeiramente.

Ao analisar o relato acima, pode-se inferir que no caso da professora investigada, apesar de citar motivos que a impulsionaram na decisão do magistério, como gostar de auxiliar os amigos nas tarefas, admirar professores com quem convivia, entre outras coisas, o fator financeiro também estava presente.

Ao concluir o ensino médio, Joana continuou no magistério, haja vista que teria duração de três anos. Ingressou no curso de fisioterapia - IMESPP - Instituto Municipal de Ensino Superior de Presidente Prudente, que logo foi incampada pela Universidade Estadual Paulista. Sendo assim, cursou o primeiro ano da universidade junto ao terceiro e último ano do magistério. Quando terminou o curso de fisioterapia, mudou-se para Bauru - SP, onde cursou Mestrado em Educação para Ciências na mesma instituição (UNESP). Em consequência do seu curso superior, trabalhou por vários anos na área da saúde, onde além do mestrado, fez outros cursos de aprimoramento.

Em 2003, surgiu a oportunidade de lecionar no ensino superior, na Universidade do Oeste Paulista (UNOESTE) o que fez com que voltasse para Presidente Prudente. De volta ao meio acadêmico, Joanadecidiu ingressar na educação básica. Prestou concurso para professora do estado de São Paulo e começou a fazer o curso de pedagogia na UNESP de Presidente Prudente. Assim, começou a lecionar em fevereiro de 2006 e teve a conclusão de sua segunda graduação em 2009. 
Penso que os dois cursos superiores, o mestrado $e$ os cursos de aprimoramento me ajudaram a desenvolver habilidades que já possuía, como capacidade de explicar, descrever, organizar. Também, pude aprender e me aprofundar em tópicos que conhecia como: tipos de avaliação, objetivos de avaliar, tipos de erros, reflexão em ação, $P C N s$, temas transversais, projetos, planejamento, rotina escolar e outros(JOANA, 2017).

Ainda segundo a professora, por já ter atuado na área da educação, o curso de pedagogia contribuiu com fundamentações teóricas para refletir sobre sua prática docente, como por exemplo a escolha dos materiais utilizados nas aulas, as metodologias e principalmente a formulação de novas estratégias diante às dificuldades que surgiam. Sobre o processo de reflexão Alarcão (2003) diz que:

[...] os professores desempenham um importante papel na produção e estruturação do conhecimento pedagógico porque refletem, de uma forma situada, na e sobre a interação que se gera entre 0 conhecimento científico [...] e a sua aquisição pelo aluno, refletem na e sobre a interação entre a pessoa do professor e a pessoa do aluno, entre a instituição escola e a sociedade em geral. Desta forma, têm um papel ativo na educação e não um papel meramente técnico que se reduza à execução de normas e receitas ou à aplicação de teorias exteriores à sua própria comunidade profissional (ALARCÃO, 2003, p. 176).

Joana reforça a colaboração do curso de pedagogia em seu crescimento não só profissional, mas sobretudo pessoal, uma vez que declara ser de extrema importância o domínio de conteúdos técnicos, mas não ignora o fato de que pode aprender muito ao ensinar. Segundo ela, "[...] os alunos são sujeitos em busca de conhecimento e merecem receber o melhor que eu possa dar.[...]" (JOANA, 2017).

Ao ser questionada quanto às principais dificuldades, dilemas e tensões próprios do universo educacional, a professora menciona algo comum nos discursos de muitos docentes. A mesma diz que com o passar dos anos, a experiência ajudou-aase organizar melhor quanto à rotina da profissão, no entanto, o excesso de tarefas institucionais e burocráticas são entraves que continuam a dificultar o trabalho, pois é dispensado um grande período de tempo nessas tarefas, tempo, que segundo Joana, poderia estar sendo utilizado no planejamento das aulas. Segundo Esteve e Fracchia (1988 apud LIMA, 1996, p. 52):

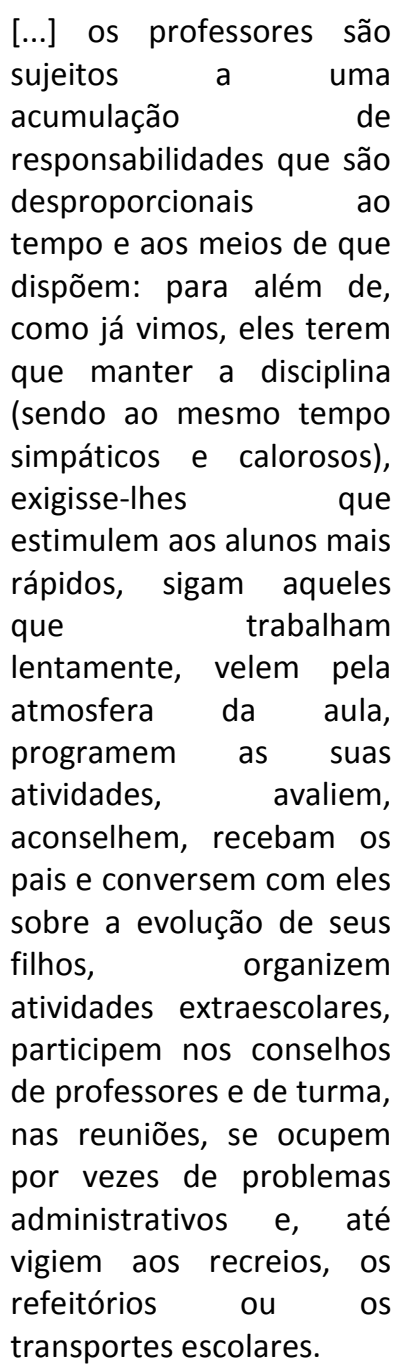

Abraham (1972apudLOPES, 2001, p.32) reforça essa ideia, quando argumenta que "ao professor atribui-se, simultânea e 
manifestamente, o papel de pai, juiz, exorcista e outros. Ele é o 'bode expiatório' e a 'esperança' de uma sociedade que transita de um modelo paternalista de domínio do indivíduo a um modelo maternalista".

Corroborando com as ideias dos autores, pode-se depreender nessa análise, que estas estão entre as principais características vivenciadas pelos professores, podendo acarretar numa variedade de problemas de caráter afetivo, psicológico e até mesmo físico. Lima (1996) denomina toda essa diversidade de tarefas atribuídas ao professor como um alargamento de funções, em que geralmente tem suas origens em processos sociais exteriores ao próprio corpo profissional. O autor ainda coloca, que essa problemática não parece ter um final breve, já que cada vez mais, os professores estão tornando-se responsáveis pelas famílias e comunidade em geral, desempenhando o papel de executor de tarefas.

Assim como a professora participante, diante das questões elaboradas, discorreu sobre sua formação inicial, o mesmo ocorreu sobre sua formação continuada, porém, algo chamou atenção em suas respostas. Percebe-se que a professora descreve com muito mais minúcias a sua formação inicial, narrando detalhes, prazeres e dificuldades, o que não ocorre no relato sobre sua formação continuada.

Joana afirma que realizou alguns cursos no decorrer da carreira, como o Pacto Nacional pela Alfabetização na Idade Certa (PNAIC) e o Letra e Vida, ambos disponibilizados pela Secretaria Municipal de Educação -SEDUC, da cidade de Presidente Prudente, em parceria com o Governo Federal e Secretaria de Educação do Estado de São Paulo. Junqueira (1990apud BITTENCOURT, 2003 p. 68) atenta para o fato de que:

[...] o que devemos considerar de vital importância é ter sempre presente que educação continuada não é apenas transmissão de conhecimentos científicos, mas, também, de atitudes em relação à utilização desses conhecimentos. Com isso afrontamos a ideologia vigente $e$ a propaganda veiculada por ela. Não se pode ignorar, entretanto, que esta visão
- formar é mudar de forma que pode implicar deformar - não marca apenas a educação continuada, mas todo o processo pedagógico, e deve deixar de ser livresco para se inserir na vivência de crianças, adolescentes ou adultos, dentro ou fora do sistema escolar institucionalizado.

O posicionamento de Joana frente às questões que abarcavam a formação continuada, assim como a análise de textos como o de Junqueira (1990) dá a possibilidade de induzir que, uma formação comprometida com o desenvolvimento dos alunos, se faz de maneira democrática, considerando os interesses dos professores, afinal, ninguém melhor do que eles para saber detectar as dificuldades presentes em suas salas de aula. Mais do que isso, vale ressaltar a importância do investimento em formações que tenham como objetivo promover um ensino de qualidade, minimizando as dificuldades de aprendizagem dos alunos, e não ter como prioridade formações continuadas que visem somente os resultados de avaliações externas.

Finalizando a entrevista, a professora participante falou de assuntos como questões políticas, pessoais e educacionais. Relatou que os saberes que foram/vêm sendo construídos no percurso da sua trajetória de vida influenciaram/influenciam na construção de suas práticas como docente e que dão a possibilidade para que exerça a profissão de maneira cada vez mais aprimorada, tomando decisões mais certeiras diante dos desafios e dificuldades que possam surgir.

Sobre os avanços e retrocessos presentes nas políticas educacionais, a professora acredita na ideia de que, para que as dificuldades no âmbito educacional diminuam, é preciso que a educação seja considerada "[...] verdadeiramente primordial [...]" (JOANA, 2017), isso abrange questões como: democracia e qualidade no ensino, oportunidade de estudar e continuar os estudos após o ensino básico de forma igualitária, para que num futuro próximo não seja mais necessário a política de cotas nas universidades, por exemplo.

Sobre os motivos que a impulsionaram e não permitiram que desistisse do ofício de lecionar, a professoradiscorreu que: 
Em primeiro lugar meus filhos que dependiam de mim e do meu esposo para custear a escola privada que frequentavam $e$ sempre demonstraram muito empenho $e$ dedicação aos estudos, então "eu como mãe não poderia fraquejar", $e$ deixá-los desamparados; as lembranças dos conselhos de minha mãe, que mesmo falecida, deixou exemplos de força e persistência. Dizia quando eu reclamava que algo era difícil: "alguém já conseguiu fazer isto? Nossa! Será que você também não consegue Joana?" Ela dava muito valor ao que eu fazia, me impulsionava a persistir e vencer! $E$ o meu "eu" minha "fé "que nos momentos de dor, angústia e desespero, faziam com que rezasse, pedisse ajuda $e$ acreditasse que tudo iria mudar para melhor.(JOANA, 2017).

Joana é uma professora que acredita na educação como forma de mobilidade social. Acredita que através de pequenas atitudes no cotidiano de sua profissão, pode mudar a trajetória de vida de seus alunos. É uma pessoa satisfeita no seu ofício de lecionar, sabe que as dificuldades são inúmeras, mas que com persistência sempre conseguiu e conseguirá superar todas. Acredita que qualidades como dedicação e empenho, são essenciais quando se quer vencer e crescer profissionalmente.

Busquei organizar minha
vida profissional e pessoal,
com intuito de conciliar e
viver de modo a não me
arrepender por não ter
tentado ou deixar de
presenciar momentos
pessoais importantes.
Aprendi e acredito que a
qualidade do tempo vale
mais que a quantidade de
tempo(JOANA, 2017).
vida profissional e pessoal, com intuito de conciliar $e$ viver de modo a não me arrepender por não ter tentado ou deixar de presenciar momentos Aprendi e acredito que a qualidade do tempo vale tempo(JOANA, 2017).
Em uma época em que se fala tanto do paradigma do mal-estar que tem acometido um grande número de docentes, analisar uma história de vida em que a insatisfação e o desconforto não fazem parte das principais características presentes no cotidiano de uma professora, foi algo, no mínimo incomum, mas ao mesmo tempo inspirador. Analisar histórias como essa, leva pesquisadores, professores e todas as pessoas que de uma forma ou outra se preocupam com o ofício do professor, ao exercício de uma reflexão mais otimista.

Não se pode esquecer ou deixar de falar sobre a questão do mal-estar docente, uma vez que ele é uma realidade, sendo que a luta para se alcançar meios de enfrentamento não pode parar. Todavia, suscitar investigações sobre o bem-estar docente é necessário e tão importante quanto. Jesus (2002, p.21) traz a seguinte consideração:

Embora consideremos
importante a investigação
sobre os fatores de mal-
estar docente, na
perspectiva de serem
encontradas soluções para
este problema, parece-nos
que esta ênfase colocada
sobre o fenômeno do mal-
estar docente e os seus
fatores pode levar a que,
entre os próprios
professores, "normal" o
considerado "seja
mal-estar docente e se
acentuem os aspectos
mais negativos da
profissão docente,
dificultando a percepção
dos aspectos positivos
dessa atividade
profissional, que também
os há.

A citação acima faz com que se pense nos inúmeros professores que ao ingressarem na carreira docente, já iniciam desmotivados e com uma visão negativa sobre a profissão. Sabe-se que as dificuldades são inúmeras e a desvalorização por parte de vários segmentos, como o governo e a sociedade de forma geral, existe. Fatores como esses e outros citados ao longo do texto, desestimulam não só professores iniciantes, mas também aqueles que já estão no exercício da docência por alguns anos, mas pensar e agir comoJoana, pode trazer momentos 
de esperança e desejo de lutar por uma educação de mais qualidade para as crianças e os profissionais. Resgatando as ideias de Freire (1996) "Se a educação sozinha não transforma a sociedade, sem ela tampouco a sociedade muda".

\section{ACHADOS E APONTAMENTOS}

Este trabalho teve como principal objetivo compreender a trajetória de formação e trabalho de uma professora. A professora selecionada atua no ensino fundamental na cidade de Presidente Prudente, interior do estado de São Paulo, com dezesseis anos de carreira nessa modalidade de ensino e com experiência em nível superior.

A partir da fundamentação teórica podese inferir que a docência ainda não é tida como profissão, considerando a ausência de algumas características para consolidar o uso do termo. Porém, encontra-se na busca constante da profissionalização e do reconhecimento da sociedade. Nesse sentido, nota-se que a carreira na docência não foi a primeira opção da entrevistada, situações financeiras e emocionais a conduziram para esse contexto.

As funções do professor na sociedade do conhecimento se alteraram, ele deixa de ser o detentor do conhecimento para ser o mediador deste. Além disso, houve um alargamento nas funções, uma vez que o professor precisa assumir muitas vezes papeis e funções que não são seus. Esses fatores diminuem a cada dia a autonomia do professor e compromete sua valorização. Joana se remete a esse fato, quando critica o excesso de burocracia, tempo este que poderia ser destinado ao planejamento de atividades mais atrativas e produtivas para os alunos.

Num primeiro momento a professora entrevistada tem uma postura razoavelmente otimista sobre a educação e sua ação na sociedade, apesar das dificuldades mencionadas, a entrevistada aponta a educação como uma possibilidade de mobilidade social e acredita que por meio de pequenas atitudes pode transformar a vida de seus alunos, porém quando questionada novamente, admite ter vivenciado momentos de desânimo na carreira.

Pesquisas como a de Gatti e Barreto (2009), demonstram a diminuição da procura pela docência. A partir da entrevista narrativa feita com a professora, percebe-se que o magistério não é a primeira opção profissional e que o fator financeiro interfere por diversas vezes no processo de formação e de permanência na profissão.

Jesus (2002) e Rebolo e Bueno (2014) trabalham um conceito oposto ao mal estardocente, o bem-estar docente, que são fatores que possibilitam a felicidade no trabalho. Joana afirma que o apego a família, a fé e as lembranças da mãe foram os motivadoresque auxiliaram a ser resiliente, em momentos difíceis. Em relação a família, menciona a necessidade do trabalho por questões financeiras. No que se refere a fé, menciona ter entrado para um grupo de pessoas religiosas. Esses grupos por diversas vezes funcionam como um apoio psicológico, ainda que pautado em uma divindade, auxiliam a manter a esperança.

O campo de pesquisa formação de professoresérelevante para o contexto atual no Brasil e essas pesquisas têm aumentado consideravelmente. Acredita-se que os conhecimentos produzidos por essa área, só redundarão em avançoes na qualidade de ensino se chegarem aos professores de educação básica por meio de formações continuadas, contínuas e/ou permanentes, assim os membros da academia devem assumir um compromisso com a difusão dos resultados de suas pesquisas.

Este estudo apresenta uma análise de dados que pode servir como fonte de reflexão e consulta para os outros profissionais que atuam no campo de formação de professores, porém, é importante reconhecer que todo e qualquer trabalho pode e deve ser aprimorado por meio de outras pesquisas, uma vez que a educação é um fenômeno complexo e em constante transformação.

\section{REFERÊNCIAS}

ALARCÃO, I. Professores reflexivos em uma escola reflexiva. São Paulo: Cortez, 2003.

ANDRÉ, M. Formação de professores: A constituição de um campo de estudos. Educação, Porto Alegre, v. 33, n. 3, set/dez, p. 174-181, 2010.

ANDRÉ, M. E. D. A. Estudo de caso em pesquisa e avaliação educacional. 3. ed. Brasília: Liber LivroEditora, 2008.

ANDRÉ, M. E. D. de. Perspectivas atuais da pesquisa sobre docência. In: BUENO, Belmira; CATANI, Denice Bárbara; SOUSA, Cynthia Pereira de et al. Docência, memória e gênero: estudos 
sobre formação. São Paulo: Escrituras, 1997. p. 65-74.

BITTENCOURT, A. B. Sobre o que falam as coisas lá fora: formação continuada dos profissionais da educação: In: FERREIRA, N. S. Formação continuada e gestão da educação. São Paulo: Cortez, 2003.p. 65-93.

BRASIL. Emenda Constitucional № 59, de 11 de novembro de 2009. Diário Oficial da União. Brasília, DF, 2009.

CHIZZOTTI, A. A pesquisa qualitativa em ciências humanas e sociais: evolução e desafios. Revista Portuguesa de Educação, Portugal, v.16, n. 02, p. 221-236, 2003.

CORTESÃO, L. Ser Professor: um ofício em risco de extinção? São Paulo: Cortez, 2002.

CLANDININ, D. J; CONNELlY, F. M. Pesquisa narrativa: experiência e história em pesquisa qualitativa. Tradução: Grupo de Pesquisa Narrativa e Educação de Professores ILEEI/UFU. Uberlândia: EDUFU, 2011.

CONTRERAS, J. A autonomia dos professores. São Paulo: Cortez, 2012.

DEMARTINI, Z. B. F. Histórias de vida na abordagem de problemas educacionais. Porto, 1988.

DINIZ-PEREIRA. J. E. A construção do campo da pesquisa sobre formação de professores. Revista da FAEEBA - Educação e Contemporaneidade, Salvador, n. 40, p. 145-154, jul./dez, 2013. Disponível em: https://www.revistas.uneb.br/index.php/faeeba/ article/view/758/531 Acesso em: 17 mai. 2017.

DUBAR, C. A socialização: construção das identidades sociais e profissionais. Porto: Porto Editora, 1997.

FERREIRA, N. S. Formação continuada e gestão da educação no contexto da cultura globalizada. In: FERREIRA, N.S.Formação continuada e gestão da educação. São Paulo: Cortez, 2003. p. 17-42.

FREIRE, P. Pedagogia da autonomia: saberes necessários à prática educativa. 6 . ed. Rio de Janeiro: Paz e Terra, 1996.
GARCÍA, C. M. Estrutura conceptual da formação de professores. In: GARCÍA, C. M. Formação de Professores: para uma mudança educativa. Porto: Porto Ed. 1999, p. 18-46.

GATTI, B. A.; BARRETTO, E. S. S. Professores do Brasil: impasses e desafios. Brasília: Unesco, 2009.

GATTI, B. A.; BARRETO, E. S.; ANDRÉ, M. E. D. de A. Políticas docentes no Brasil: um estado da arte. Brasília: UNESCO/MEC, 2011.

GIL, A. C. Métodos e técnicas de pesquisa social. 6. ed. São Paulo: Atlas, 2008.

HARGREAVES, A. Ser professor na era da insegurança: In: ADÃO, A.; MARTINS, E. (Org). Os professores: identidades (re) construídas. Lisboa: Edições Universitárias lusófonas, 2004, p. 37-54.

JESUS, S. N. de. Perspectivas para o bem-estar docente: uma lição de síntese. Porto: ASA, 2002.

JOANA. Questionário I. Entrevistadores: Vanessa Helena Seribelli, Aline de Souza, Cinthia Magda Fernandes Ariosi, Ariadne de Sousa Evangelista. Local, 2017. Questionário concedido para pesquisa.

LARROSA BONDIA, J. Notas sobre a experiência e - saber de experiência. Revista Bras. De Educação, n.19, p. 20-28, jan./abr, 2002. Disponível em: http://www.scielo.br/scielo.php?script=sci arttex t\&pid=S1413-

$24782002000100003 \& \operatorname{lng}=$ pt\&tlng=pt. $\quad$ Acesso em: 17 mai. 2017.

LIMA, J. A. O papel de professor nas sociedades contemporâneas. Educação, Sociedade \& Cultura, n. 6, p. 47-72, 1996.

LOPES, A. Mal-estar na docência? visões, razões e soluções. Porto: ASA, 2001.

MARIN, A. J. Educação continuada: introdução a uma análise de termos e concepções. Caderno CEDES, n. 36, p. 13-27, 1995.

MOMBERGER, C. D. Formação e socialização: Os ateliês biográficos de projeto. Educação e Pesquisa, São Paulo, v. 32, n. 2, p. 359-371, 
mai./ago, 2006. Disponível em: http://www.scielo.br/scielo.php?script=sci arttex t\&pid=S151797022006000200011\&lng=pt\&t|ng=pt. Acesso em: 17 mai. 2017.

NÓVOA, A. (Coord.). Os professores e sua formação. Lisboa: Dom Quixote, 1992.

QUEIROZ, M. I. P. de. Relatos orais: do indivisível ao divisível. In: SIMSON, $O$. de $M$. V. Experimentos com histórias de vida: Itália e Brasil. São Paulo: Vértice, 1988, p. 14-43.

REBOLO, F.; BUENO, B. O. O bem-estar docente: limites e possibilidades para a felicidade do professor no trabalho. Acta Scientiarum. Education, Maringá, v. 36, n. 2, p. 323-331, jul./dez., 2014.

RIOS, T. A. Compreender e ensinar: por uma docência de melhor qualidade. São Paulo: Cortez, 2001.

SCHON, A. S. Formar professores como profissionais reflexivos. In: NÓVOA, A. (org). Os professores e sua formação. Lisboa, Dom Quixote, 1997, p. 77-92.

SOUZA, E. C. Diálogos cruzados sobre pesquisa (auto) biográfica: análise compreensivainterpretativa e política de sentido. Revista do Centro em Educação UFSM, Santa Maria, Rio Grande do Sul, v. 39, n. 1, p. 39-50, jan./abr. $2014 . \quad$ Disponível em: https://doi.org/10.5902/1984644411344. Acesso em: 20 mai. 2017.

ZAINCO, M. A. S. Desafios da universidade contemporânea: $O$ processo de formação continuada dos profissionais da educação. In: FERREIRA, N. S. Formação continuada e gestão da educação. São Paulo: Cortez, 2003. P. 187217.

Submetido: $17 / 11 / 2018$

Correções obrigatórias: 08/02/2019

Aceite final: 16/02/2019 